\title{
From idealistic rookies to a regional leader: The history of health technology assessment in Poland
}

\author{
Rafał Niżankowski \\ Jagiellonian University and University Hospital \\ Norbert Wilk \\ Arcana Institute
}

In 1989, Poland started to slowly release itself not only from the burden of a half-century of communist indoctrination and soviet exploitation, but also from the consequences of the Semashko model of healthcare organization: low doctors' salaries, primary care based on multispecialty groups, overdeveloped hospital infrastructure, and limited access to sophisticated interventions overcome by patients' unofficial payments.

A few years after the 1998 workshop on health technology assessment (HTA) in Budapest, the first HTA reports were elaborated in the National Center for Quality Assessment in Health Care, which could mark the beginning of HTA in Poland. Several individuals and organizations have been involved in developing HTA, both from noncommercial and commercial standpoints.

A goal to establish a national HTA agency appeared among the priorities of the Polish Ministry of Health in 2004 and was realized a year later. The Agency for HTA in Poland published guidelines on HTA and established a sound and transparent two-step (assessment-appraisal) process for preparing recommendations on public financing of both drugs and nondrug technologies. The recommendations of the Agency's Consultative Council were warmly welcomed by the public payer. However, the recent major restructuring of the Agency and new drug reimbursement decisions aroused doubts as to keeping transparency of the decision-making processes.

Keywords: Health technology assessment, Poland, History

\section{THE HEALTHCARE SYSTEM IN POLAND}

In contrast to many other countries, the end of the Second World War did not mean independence for Poland. The Soviet Red Army imposed an autocratic political system led by a dominating communist party. Health care for more than 40 years after 1945 was influenced by ideas coming from the Soviet Union. This system was called the Semashko model, an alternative to Bismarck and Beveridge that dominated in Europe and the United Kingdom. It was based on an assumption that proper health care could be offered by state-owned services, financed like state administration with global budgets limiting personal and nonpersonal expenditures. Its ma- jor characteristics included salary payment (at a relatively low level), primary care based on multispecialty groups in contrast to general practitioners, extensive development of hospital beds as well as limited access to more sophisticated interventions, and a common habit of patients' unofficial payments to overcome access constraints. After the great political Change of 1989 initiated by the Solidarity movement, the healthcare system in Poland was perceived as extremely inefficient and remained a field that demanded substantial improvements.

During the first few years after reaching independence in 1989, efforts of reformers were directed toward: (i) transforming healthcare organization from state budgetary units 
into more independent public hospitals and public clinics financed with historical global budgets without detailed spending directives; (ii) education and implementation of family physicians working in their own private practice financed with public funding on a capitation basis, following Dutch and Danish models as a core element of primary care instead of the Semashko team of specialists in internal medicine, pediatrics, gynecology, and surgery; and (iii) establishing schools of public health for education of mainly healthcare managers, a profession that did not exist in the previous communist period.

The half-century overdeveloped infrastructure of the healthcare system was financed inadequately to the needs and demands. Consequently, the infrastructure steadily decapitalized and wages of doctors and nurses were relatively very low compared with similar professionals outside health care. There was I but universal and strong belief among physicians that the major reason for their low incomes was a political limitation on the part of state budget dedicated to health care. They assumed that implementation of health insurance and split roles of payer and provider would solve most of the existing constraints.

The reform initiated in 1997 resulted in major changes in the financial mechanism after 2 years. Instead of the part of the state budget voted by the Parliament, healthcare funds became a sum of predefined percentage deductions from wages and salaries, paid by an employer and collected separately from other taxes. Because the idea of universal coverage persisted, the state budget was obliged to pay for the unemployed. Sixteen regional sickness funds were created and financed health services according to contracts that also imposed complicated requirements imposed on providers. It resulted in a dramatic increase of the administrative load on both sides, an enormous unproductive bureaucracy and large regional differences in access, prices, and scope of care.

The next major change was implemented in 2002, when the system was centralized in one unified organization, called the National Health Fund (NHF). Positive regional experiences were unfortunately abandoned and sixteen Sickness Funds were transformed into regional offices of the NHF with a central office in Warsaw. Administrative staff expanded. Hospitals were financed on the fee-for-service principle with yearly limits for the numbers of each provided service as defined by the NHF in the contract. The Warsaw NHF bureaucracy arbitrary decided on prices for each intervention, thus making some of them very financially attractive (e.g., coronary angiography, dialysis) and some far below the actual costs of providers. That led to a rapid development of private providers who offered selected, profitable procedures while not caring for "costly" patients. Needless to say, public hospitals developed large debts, as they are legally obliged to offer care even if it is not fully reimbursed by the NHF or is economically irrational.

Periodic changes of basic conditions for NHF-provider contracts, made by NHF, repeatedly destabilized the system.
Recently, in the middle of this year, NHF changed the payment scheme from the fee-for-service to a diagnosis-related group-like system, with hardly any adequate calculations and testing phase. The results so far seem to be unexpected decreases of financial resources of even -30 percent in some areas with moderate increases in others.

There are no patient co-payments for hospitalization or outpatient visits. But at the same time, Poland has one of the highest co-payment ratios for reimbursed pharmaceuticals among European Union (EU) countries. Pharmaceuticals for outpatients are financed with public funds through two strands: the list of reimbursed drugs, managed by the Minister of Health, and the therapeutic drug programs managed by the President of NHF.

The list of reimbursed drugs officially falls under the requirements of the EU Transparency Directive (180 days to make an aggregate decision both on reimbursement and price, objective and verifiable criteria, possibility of appeal) and is announced in a form of an ordinance of the Minister of Health. In practice, therapeutic drug programs contain particularly expensive drugs for relatively small populations, whereas the list of reimbursed drugs is a more general tool for public funding of drugs.

\section{EARLY DAYS OF HEALTH TECHNOLOGY ASSESSMENT IN POLAND}

The development of health technology assessment (HTA) in Poland was largely because of (i) the eagerness and idealism of the few individuals who devoted some years of their lives to disseminate this idea and bring it closer to Polish practice, and (ii) increasing demands for more services and existing difficulties in rational selection of what should be financed from public funds. Naturally, the simple play of chances cannot be excluded, although there is a popular proverb in Polish: luck favors those who are better.

As early as a few years after the end of communism in Poland, individuals in charge of modernization of the healthcare system were looking for new promising tools. During the Drug Information Association 1992 Annual Meeting in San Francisco, in the United States, the director of the Polish Ministry of Health, Department of Science and Education, presented a vision of improvement of postcommunist health care thanks to special development of the very new activities in three interrelated areas: Health Technology Assessment, Clinical Epidemiology, and Quality Assurance. None of these knowledge bases or skills existed in the country at that time.

That vision began to be implemented only 2 years later, when the National Center for Quality Assessment in Health Care (NCQA [9]) was founded by the Minister of Health to inspire and support activities aimed at improvement of effectiveness, safety, and other aspects of quality of healthcare services provided within the Polish healthcare system. The proponent of NCQA was the coauthor of this study (R.N.), who was in charge of establishing it and acted as a 
director until 2002. NCQA introduced accreditation of hospitals, started to assess quality of outcomes from the perspectives of professionals (quality indicators, patient quality registers) and consumers (patient satisfaction surveys). The next step was to create national guidelines based on scientific evidence to supplement existing activities to reduce the variation of medical practice in the country. With this aim, the Standardization Bureau was established within NCQA in 1997 with the new staff who got their initial training in evidence-based medicine (EBM) from Roman Jaeschke from McMaster University, Canada.

It was during the meeting of the International Society for Quality Assurance in Health Care in October 1998 in Budapest that a few NCQA staff members were invited by Laszlo Gulacsi (the organizer of the Budapest meeting and old friend of the NCQA director) to the preconference workshop on HTA. For the first time, they had a chance to listen to David Banta, Egon Johnson, and many other fascinating people, thanks to whom they realized the general importance of HTA and its potential impact in Poland. Soon after, the Standardization Bureau started to work both on practice guidelines for providers and technology assessments perceived as specific guidelines for decision makers. This resulted in the first HTA reports consisting of two elements: (i) comparative analysis of clinical effectiveness and safety based on systematic reviews of all available scientific evidence and respecting Cochrane requirements, as well as (ii) economical analysis with use of modeling techniques and local utilization and cost data.

With the above taken into account, it could be estimated that HTA in Poland has a history of roughly 10 years.

Another important event for those involved in that new activity in Poland was the International Workshop on EBM and HTA organized in October 2000 in Niedzica, Southern Poland, by NCQA and the International Society for Technology Assessment in Health Care (ISTAHC) under the auspices of the World Health Organization (WHO) Europe. The original venue of a medieval castle offered a truly unique environment for long discussions with experts, including Mitchell Sugarman and James Brevis (Kaiser Permanente, United States), Roman Jaeschke (McMaster University, Canada), Julia Chamova (SBU, Sweden), Jacek Splawinski (Drug Institute, Poland), Alesh Bourek (Institute for Quality in Healthcare, Czech Republic), Isuf Kalo (WHO Europe), and George Tombs (ISTAHC).

Reliable clinical and economic assessment of new and existing interventions soon emerged also outside NCQA. EBM was consequently promoted by the medical journal $\mathrm{Me}$ dycyna Praktyczna through publishing structured abstracts of most reliable evidence and having its staff organized in the Polish Institute of EBM (12) and through various training and other activities. Economic analysis became the interest of a few groups. The School of Public Health in Cracow introduced training in pharmacoeconomics into the undergraduate curriculum. Jacek Splawinski and Ewa Orlewska in
Warsaw initiated pharmacoeconomic analysis at the National Drug Institute. Orlewska later edited for many years a journal Farmakoekonomika (Pharmacoeconomics) and published a first textbook with the same title (11). Maciej Niewada led another group performing economic analysis in Warsaw.

Close contacts of Polish scientists with their Czech and Hungarian colleagues (mainly Ales Bourek and Andrea Rita Horvath) resulted in the HTAi 2004 First Annual Meeting held in Krakow, in southern part of Poland. In addition to the respectful world-leading HTA experts, the meeting also featured the prominent guest speaker Lech Walesa, the Noble Prize winner.

\section{INSTITUTIONALIZATION}

Poland is facing the same difficulties and problems as Western countries. Better education and growing influence of mass-media stimulated a demand for health services. Aggressive marketing blew up the population's health needs into group-interest driven demands. The increasing demands in turn face a rather slow increase of available funds. Any rational limits, like those offered by HTA, have become slowly perceived as valuable by politicians and other decision makers and gradually more appreciated.

An increase of interest by industry in having stronger arguments for reimbursement of pharmaceuticals and procedures stimulated commissioning more new HTA reports by pharmaceutical companies and manufacturers of medical devices. This was followed with a slower increase of decision-maker awareness that comprehensive HTA could make their decisions less susceptible to critique.

The Standardization Bureau within the NCQA was the first stable HTA organization. Among its staff members were Krzysztof Landa, Norbert Wilk (coauthor of this study), Jacek Wcislo, Jacek Walczak, Pawel Kawalec, Maja Laczynska, and Magdalena Wladysiuk. Until 2002, it was the sole source of training programs dedicated for those who were recipients of the HTA reports and of HTA reports performed for Ministry of Health, Sickness Funds, and pharmaceutical industry. Most of the people who are currently involved in HTA in Poland got their first HTA education there. NCQA was a natural partner for international cooperation. In 2000, it participated in two World Bank projects related to HTA. One concerned the basic benefits package and was led by the Dutch TNO, and the second organized by Public Health Foundation concerned a series of publications on public health issues, including clinical effectiveness and economic analyses.

In 2002, a radical political change of the government resulted in a substantial decrease of funding for NCQA. The Standardization Bureau was shut down and some of its staff established both public and private enterprises offering HTA reports commercially. The Krakow Branch of the Polish Society for Promotion of Quality in Health Care with Rafal Nizankowski as chairman has become active in 
economic evaluations of medical technologies. Several commercial organizations perform HTA reports predominantly for the industry. The largest are Arcana Institute led by Grzegorz Nogas and Jacek Walczak (4) and HTA Consulting led by Krzysztof Landa, the former head of the Standardization Bureau (6).

In the middle of 2004, a new government was nominated. One of the authors of this study (R.N.) was appointed deputy minister of health. Establishing a national HTA agency appeared among the priorities of the new ministry. At the beginning of 2005, a team of experts was nominated and prepared basic documents that would regulate the new institution. It was decided that its main aim would be development of the evidence-based recommendations for the Minister of Health and the president of the National Health Fund. Two major processes performed by the Agency will be (i) to perform systematic assessment of the technology in question either through preparing HTA internally or by external academic commissioners, or critically verify by the staff members of the Agency analyses submitted with an application for reimbursement; (ii) to perform value judgment of technology (critical appraisal) by combining results of the assessment with social values and formulate final recommendations for the Minister of Health (a task to be performed by Consultative Council consisting of external experts and highly esteemed people working part time for the Agency).

An HTA-based decision-making system in Poland is aimed at financing from public resources all those health technologies that are worth it, while at the same time its task is to prevent waste of limited public resources on technologies of low clinical effectiveness or cost-effectiveness.

In September 2005, the Minister of Health signed a decree that formally established the Agency for Health Technology Assessment in Poland (AHTAPol, Polish acronym AOTM [2], current decree [14]). After an initial organizational period, the Agency undertook its tasks in February 2006. Dr. Waldemar Wierzba became the first director of AHTAPol. He employed the coauthor of this study (N.W.) as a deputy director for HTA and international collaboration. It is worth noting that, in addition to tasks associated with HTA, the Agency was given an order to coordinate the most politically sensitive process, that is, formulation of the basic benefits package (BBP). Work on BBP attracted most of public attention, which led to a relatively quiet and calm environment for implementation of the technology assessment process of reaching decisions on financing health technologies with public funds.

Until March 2007, HTA reports have been prepared according to various plans, because there were no specific requirements concerning their preparation, that would be generally accepted by the community of experts. Authors of reports freely adapted some of the foreign models and sometimes developed their own. In 2001, Orlewska and Mierzejewski published "Polish guidelines for conducting financial analysis (project)" (10). Due to numerous serious reserva- tions, this proposal was not accepted by those who were interested in sound HTA.

The very first activity of the newly established Agency was to formulate "Guidelines on health technology assessment" (1). During several months of 2006-07 the guidelines were prepared by the task force of eleven experts appointed by the Agency, chaired by the coauthor of this study (R.N.). After the first proposals limiting technology assessment only to economic analysis, the task force finally agreed that a model similar to that used in Canada will be adopted. To be considered complete, an HTA should contain three main analyses: clinical effectiveness analysis, economic analysis, and healthcare system impact analysis. Each related to important issues.

\section{Clinical Effectiveness Analysis}

Complete and credible clinical evidence concerning a particular subject is to be used. In addition, a systematic review is required, and it should include the following: (i) a detailed description of the method of literature search; (ii) inclusion and exclusion criteria for the studies, defined a priori and used independently by two investigators; (iii) assessment of quality of the included studies; and (iv) meta-analyses should be included, if possible.

\section{Economic Analysis}

First, the perspective of the payer for health care (the public payer-National Health Fund or Ministry of Health, the patient, and optionally other payers) should be performed in each case. Additional analysis from the social perspective (taking into account indirect costs) could be presented. Second, the economic analysis should always include presentation of cost and consequence data irrespectively of costeffectiveness or cost-utility analysis. Third, a cost-benefit analysis is not recommended. Fourth, data concerning unit costs should be collected from at least six institutions of different reference levels. And fifth, the assumed discount rate in basic analysis is 5 percent for costs and health-related outcome measures; in sensitivity analysis it is 0 percent for costs and health-related outcome measures and 0 percent for health-related outcome measures and 5 percent for costs.

\section{Healthcare System Impact Analysis}

There are three key aspects to this healthcare system impact analysis: (i) the impact of the technology in question on the annual healthcare budget over several years after introduction of the technology (usually until establishing market balance or for at least 2 years after beginning finance with public resources) is required; (ii) optional special conditions for introduction of the technology (specific personnel training, development of a new clinical guidelines, change of existing diagnostic procedures) should be described, along with related costs; (iii) the relationship between effectiveness and equity should be discussed. Therefore, a population 


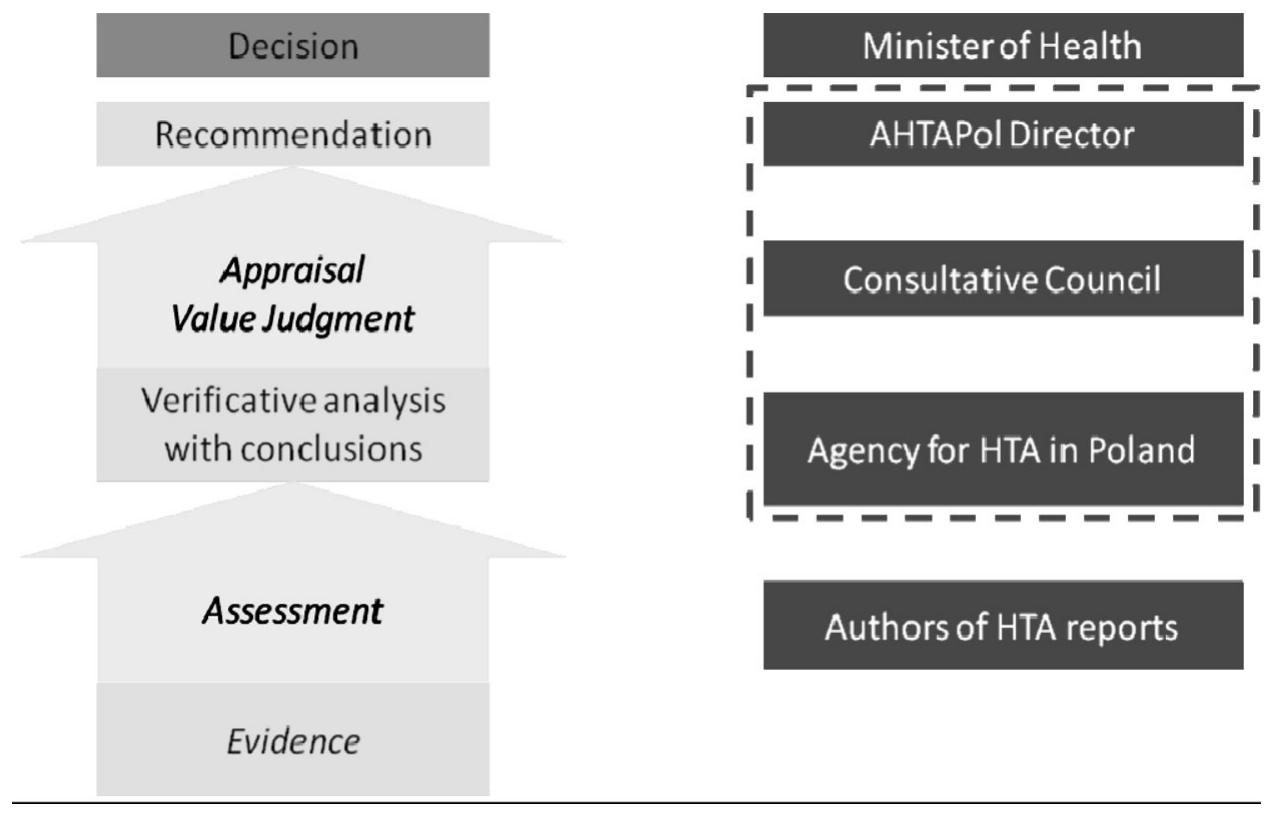

Figure 1. The model for drug reimbursement decision making in Poland. AHTAPol, Agency for Health Technology Assessment in Poland; HTA, health technology assessment.

likely to benefit mostly from the technology should be defined and the expected positive as well as negative effects described.

Polish HTA Guidelines were published in March 2007. For the past 1.5 years, they improved the credibility of HTA analyses, increased reproducibility of the results, and limited the possibility of drawing different conclusions by experts evaluating the same technology. Recently, the Agency considered updating the guidelines. A few meetings of a new task force suggest the possibility of minor if not cosmetic changes to the original version.

In 2007 and 2008, the Minister of Health referred to the Agency more than ninety submissions for reimbursement of new pharmaceuticals that had waited even five or more years without any decision. The Agency organized assessment of submitted materials and its critical analysis in two teams, one working in Warsaw and the other working in a branch office in Krakow. The AHTAPol Consultation Council led by one of the authors (R.N.) started to formulate first recommendations for the Minister in August 2007.

Since its inception in September 2005, the Agency has survived two changes of the government. As a consequence of the recent one, a newly nominated director of the Agency initiated severe dismissals of the staff and reshaping the structure by closing down the Krakow branch office.

Investing in human resources has been on the top of the agenda of the Agency during its first 2 years. Staff benefited from extensive internal training and international exchanges thanks to the Twinning Project "Transparency of National Health System Drug Reimbursement Decisions". One of the coauthors (N.W.) was responsible for the general scope of that project and application for its funding (Fig. 1). It was realized in cooperation with the French Agency HAS (5). During the 2-year project, EU experts performed a thorough systemic diagnosis of the Polish reimbursement system and trained several hundred individuals in doing and using HTAs.

\section{“It's the Transparency, Stupid!”}

This is a paraphrase of the motto "It's the economy, stupid" that was used by Bill Clinton during his first presidential election campaign in the United States. Transparency was the issue in the Polish situation. The latest changes brought about some impatience within the stakeholders as to keeping transparency of the procedure of reaching a recommendation. During the past 2 years, the coauthor of the study (N.W.) introduced four Transparency Programs. Two of them regarded the methods of collecting experts' opinions consulted in the process of developing a recommendation. Requests for opinions were directed to a so-called national specialist (a person, mostly academic, nominated by a minister of health as his/her advisor for particular specialization) and a president of a scientific society in a given field of medicine. The other request for experts' opinions was posted on the Agency Web site, and anybody could present his position under the sole condition of attaching a statement with the conflict of interest disclosure.

The other transparency program "Producer's commentary" could be regarded as the most important one. A drug or device producer or someone else who submitted an application for reimbursement with HTA analyses was provided 
with the same set of documents about the technology in question and at the same time as the Consultative Council members, and was asked for a commentary. There were no restrictions to the content of the commentary as long as it did not exceed three standard pages. These commentaries were analyzed by those internal analytical staff members who originally verified the submitted documents, and an analytical position was produced. Both documents, that is, producer's commentary and analytical position, were submitted to the Consultative Council and supplemented the previously prepared materials. In that way, the producer's input could be considered while the recommendation was discussed.

The fourth transparency program was called "Fully Transparent." After issuing a recommendation, the Agency asked the producer for its consent to put all the materials about the technology in question on the Agency Web site. Should certain fragments be kept secret, a legal justification had to be presented. It was in line with the Polish constitution and the law on access to public information.

The positive experience with the above-mentioned programs was reported during the conference in the Ministry of Health in June 2008 (13). The Industry and other stakeholders representatives were more than satisfied with that level of transparency, the Agency declared that these programs would continue. Unfortunately, several months passed and the level of transparency went down as the recommendations prepared by Consultative Council recently have become secret until the acceptance by the Minister of Health (3). Reacting to this, the members of the Consultative Council issued an open letter to the Minister requesting a change in that regulation (7).

Stakeholders are becoming more and more aware of their rights to know and to be given an opportunity to openly influence the process at least through their commentaries to critical analysis of submitted HTA materials. If there is nothing to hide, why hide anything? Who's afraid of transparency?

\section{PRESENT DAY AND FUTURE OUTLOOK: HERCULES AND THE ORACLE}

Currently, the Agency is nearly fully engaged in reducing almost a decade-long backlog of reimbursement decisions. Up to a hundred applications are pending to be concluded with recommendations. During the past year, approximately thirty applications were finalized. A new approach of the Minister of Health was observed during the past few months. If the minister is not satisfied with a conclusion of recommendation, he returns the materials to the Agency for repeated assessment and appraisal. The number of applications returned by the Minister seems to gradually increase.

As public funds for reimbursement of drugs and other health technologies are drying up (according to the NHF plan for 2009 a $0.5 \%$ decrease of reimbursement budget [8]), the need for HTA objectivity should further intensify. Recently, the spokeswoman for the President of the National Health Fund said: "The NHF perceives AHTAPol to be an oracle. If they say a technology is worth financing, we will finance it, if they say no, we are not going to pay for it."

In the country discussion about legislative reinforcement of the Agency, its goals and aims and the role of evidence in reimbursement decisions is currently ongoing. Many elements in decision-making process are already based on credible scientific evidence. One very important element of this process is still nearly lacking in the country, that is, the ability to include risk sharing modes into the reimbursement decisions. Despite many actual weaknesses, we are quite optimistic. We can see arguments that the general direction of the progress that started 10 years ago in NCQA will remain unchanged. We believe that Poland will be recognized as a strong European partner, even a regional leader in the field of HTA.

But there is a fly in the ointment - a recently announced decision on funding palivizumab in preventing newborns' respiratory syncytial virus infections despite a negative recommendation of the AHTAPol Consultative Council and several positive decisions in a recent draft amendment to drug reimbursement lists without any prior recommendation of the Council. Nevertheless, we still hope for more rationality anchored in evidence instead of keeping up appearances for taxpayers' money.

\section{CONTACT INFORMATION}

Rafal Nizankowski, MD, PhD (r.nizankowski@gmail.com), Associate Professor, Department of Angiology, Jagiellonian University; Chief, Department of Angiology, University Hospital, 8 Skawinska, Kracow 31-066, Poland

Norbert Wilk, DMD (norbert.wilk@inar.pl), Director of Research and Quality Development, Arcana Institute, Plk. Dạbka 8, Krakow 30-732, Poland.

\section{REFERENCES}

1. AHTAPol. Guidelines for health technology assessment. http://www.aotm.gov.pl/assets/files/wytyczne_hta/Wytyczne_ HTA_w_AOTM.pdf (accessed November 24, 2008).

2. AHTAPol. Homepage. www.aotm.gov.pl.

3. Ajencja Oceny Technolojii Medycznych. Pacjenci moga odzyskać zdrowie niezależnie od leków lub za ich pomoca. [Communication]. http://www.aotm.gov.pl/index.php?id = 43 (accessed November 24, 2008).

4. Arcana Institute. Homepage. www.inar.pl.

5. Haute Autorite de Sante. Homepage. www.has-sante.fr.

6. HTA Consulting. Homepage. www.hta.pl.

7. Krajewski R. Letter to the Minister of Health. http://www. aotm.gov.pl/assets/files/rada/rada_konsultacyjna.pdf (accessed November 24, 2008).

8. MP Online. Ostrzeżenie przed obniżeniem nakładów na refundacje leków. http://www.mp.pl/kurier/index.php?aid = 
$41472 \& 1=918 \& \mathrm{u}=16578079 \&$ tc $=686 \mathrm{D} 40 \mathrm{CBCD} 7 \mathrm{~F}-$ 48E59A9D7CA70C657A33 (accessed November 24, 2008).

9. NCQA. Homepage. www.cmj.org.pl.

10. Orlewska E, Mierzejewski P. Polish guidelines for conducting pharmacoeconomic evaluation. Farmakoekonomika. 2000; (suppl 1):1-20.

11. Orlewska E. Podstawy Farmakoekonomiki [Basic pharmacoeconomics]. Warszawa: Oficyna Wydawnicza Unimed; 1999.

12. PI-EBM. Homepage. www.ebm.org.pl.
13. Wilk N. Doświadczenia pilotażu programów przejrzystości. http://archiwum.aotm.gov.pl/pliki/pub/pl/prezentacja_Norbert_ Wilk.pdf (accessed November 24, 2008).

14. Zarzadzenie Ministra Zdrowia zmieniające zarządzenie w sprawie Agencji Oceny Technologii Medycznych [Decree of the Minister of Health on the Agency for Health Technology Assessment in Poland]. http://www.aotm.gov.pl/ pliki/onas/zarzadzenie_10_09_2008.pdf (accessed November 24, 2008). 